\title{
The Development of E-commerce in the Context of COVID-19
}

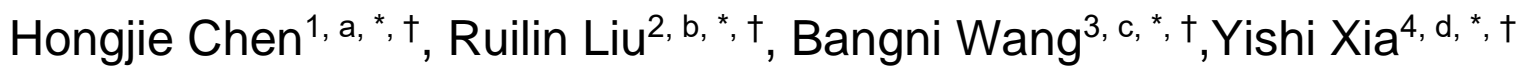 \\ ${ }^{1}$ Beijing Royal School Beijing 100000China \\ 2Zhengzhou Foreign Language School, Zhengzhou 450000, China; \\ ${ }^{3}$ School of Business Macau University of Science and Technology Macau 999078 China; \\ ${ }^{4}$ Shanghai Experimental Foreign Language School Shanghai 200082 China. \\ *Corresponding author: a2631759389@qq.com b718453394@qq.com \\ c2009853PB011005@student.must.edu.mod2363441572@qq.com
}

\section{'These authors contributed equally.}

\begin{abstract}
With the outbreak of COVID-19, the national economy has been depressed because people cannot produce and assume goods normally. Thus, offline shopping become a problem in daily life. People have to adapt to the new social environment to make a living. Apparently, Ecommerce is the most important result of economic development brought by the experiences of the business method during this pandemic. This paper introduces and uses the SWOT analysis method to list the strengths, weaknesses, opportunities, and threats of E-commerce. There's a case study of one of the most popular E-commerce companies in China, JingDong, in order to illustrate the strength of selling products online during COVID-19. This paper mainly focuses on the E-commerce development in China during the pandemic, and the research result shows that the platform business model, specifically the E-commerce, is the best choice for developing enterprises during the pandemic. How the business should choose for their progress can be found in this paper as well. Although E-commerce might have vices in some parts, due to the high profits brought to the enterprises by E-commerce, more people may still be willing to engage in the operation of Ecommerce, and expand the team of Chinese E-commerce, thus promote economic prosperity as soon as possible.
\end{abstract}

Keywords: E-commerce, COVID-19, SWOT analyze, Development, Effect

\section{Introduction}

Since 2019, the appearance of the COVID-19 virus, even now people's lives have been hugely impacted. The COVID-19 pandemic has restricted not only people's work but daily life. Because of the high infectivity of the pandemic, the government of China ordered people to stop most of the offline activities. These activities involve a vast range of life, such as the offline operation of the company, the offline teaching of the school, and schools are not allowed to resume offline courses up to time. Even going outdoors and purchasing groceries have become wild wishes. Thus, people must work, learn, and shop at home. As they break out of the COVID-19 pandemic, the development of the network has been progressing unexpectedly. January 18, according to the National Bureau of Statistics' 2020 Annual report on China Economy, total retail sales of consumer goods for the year is 391981 billion yuan, decreasing 3.9\% from 2019. National online retail sales are 117601 billion yuan, an increase of $10.9 \%$ over the previous year. Among them, online retail sales of physical goods amounted to 9759 billion yuan, an increase of $14.8 \%$, accounting for $24.9 \%$ of total retail sales of consumer goods, a rise of $4.2 \%$ over 2019. Since people's dependence on the internet has been shown during the pandemic, many companies grab the opportunity and change their operation mode from offline to online. This makes people's daily lives more convenient than before the rapid development of the network.

Business models emerged in the 1950s and were widely used in the 1990s. The business model is the bridge that connects both buyer and seller. Finding an appropriate business model for the company will be helpful for improving the company's development. Different enterprises need to choose a competitive business model based on their own need according to their unique result. Business models 
are composed of nine factors. They are value proposition, target customer, customer relationships, cost structure, revenue model, core capabilities distribution channels, value configuration, and partner network. Those are the factors that business managers need to be concerned about when choosing their own business model. Typical business models are divided into several types: warehouse business model, direct supply business model, monopoly business model, and platform business model [1]. Warehouse business model means the company delivers goods directly to consumers without passing through third-party platforms. For example, the GOME in China. It corporates with logistic companies, and GOME delivers its product directly to their customer through that company. Now supply business model refers to the industry that only supplies their product to a particular company, which means they have a contract that can only trade with each other. Directly supply business models are standard in the Liquor industry because the liquor industry has massive capital flow, and the market range of sale is small so that the product can flow quickly in the market.

The company can process the trade more smoothly and efficiently. A monopoly business model is suitable for a company that has already had a brand in the market. It needs enterprise to earn a certain amount of profit, which means its selling should be stable. GREE ELECTRIC APPLIANCES, INC. OF ZHUHAI is one of the examples to illustrate the monopoly business model. Platform business model is a model which shows an upward trend according to all business models nowadays. It refers to a platform that links two or more groups and is designed to meet the needs of both parties [2]. Platform business model based on value creation, value transmission, value distribution, and value realization between terminal customers, suppliers, and platform enterprises [3]. The development of globalization makes people focus more on a network; digital marketing is one of the results of that development. With the influence of COVID-19, online shopping has developed rapidly; E-commerce has grown into the leadership of the platform business model. Commonly refer to Jing Dong and Taobao in China. Using domestic industry as an example, Jing Dong is a platform, and it is the tool that creates connections between company and customer. Platform business model is convenient for almost everyone. Since trade all happened online, people don't need to pay extra attention to an offline store.

According to the research above, the documents we have let us have deep insight into the study of the business model. However, after the happening of the COVID-19, whether the current business model is still appropriate or creates a new business model is apparent. Therefore, this article mainly focuses on studying E-commerce and using SWOT analysis strategy. E-commerce serves as the studying subject, researching the development of business models under the context of COVID-19.

\section{Data and methods}

\subsection{Business case and data selection}

In the economic context of the COVID-19 epidemic, we selected Jing Dong, a leading retail ecommerce company, to compare online and offline sales.

Jing Dong is a self-owned B2C e-commerce company in mainland China, with Jing Dong Mall, Jing Dong Finance, O2O, and Overseas Business Units. Its Jing Dong Home and Jing Dong Convenience Store are the carriers and experience stores of Jing Dong's offline services. Jing Dong Mall is a leading technology-driven e-commerce company and retail infrastructure service provider in China. Its advanced retail infrastructure enables consumers to buy anything they want, anytime, anywhere. The company has opened its technology and infrastructure to partners, brands, and other industries. Jing Dong is the largest retailer in China, a NASDAQ 100, and a Fortune Global 500 company. The overall financial report of Jing Dong is shown in Table 1. 
Table 1. 2016-2020 Jing Dong Financial Annual Report Income Statement (Billions of yuan)

\begin{tabular}{cccccc}
\hline & $\mathbf{2 0 1 6}$ & $\mathbf{2 0 1 7}$ & $\mathbf{2 0 1 8}$ & $\mathbf{2 0 1 9}$ & $\mathbf{2 0 2 0}$ \\
\hline Operating revenue & 2601.22 & 3623.32 & 4620.20 & 5768.88 & 7458.02 \\
Gross profit & 394.23 & 508.15 & 659.54 & 844.21 & 1091.08 \\
Operating profit & -21.45 & -8.35 & -26.19 & 89.95 & 123.43 \\
\hline
\end{tabular}

Information compiled by the author

\subsection{SWOT qualitative analysis model}

SWOT analysis also called situational analysis or Dawes matrix, is a kind of competitive enterprise situation analysis method, which was first proposed by Harvard Business School in the U.S. SWOT analysis is to systematically analyze and study the strengths, weaknesses, opportunities, and threats of an enterprise, to enhance the power of the enterprise, use the options to reduce the hazards, maintain the dynamic balance between the internal resources and the external environment, and achieve the strategic development goals set by the enterprise. strategic development goals [4].

\subsection{Strengths and weaknesses (SW)}

Strengths are internal factors that an organization have control over. Strengths are helpful in respect of the SWOT objective. It includes many aspects of a company, such as financial, technological and customer services. In financial aspect, a company can have robust balance sheet, cash flow and credit rating. It has plant and machines advantages in technology. And it also has great customer services advantages in marketing, sales, and reputation [5]. Furthermore, weaknesses are harmful for swot model. These weaknesses can lead to take advantage of an opportunity. Weaknesses include many aspects factors, just like financial weaknesses have high debt- liquidity ratio, technology, poor employee morale and others.

\subsection{Opportunities and threats (OT)}

Opportunities are external factors of the company, include new products and markets, lifting foreign market barriers and competitors' mistakes. These all provide new chance and opportunities for a company development [5]. Threats are external and harmful to the organization. A threat can be a hostile takeover bid and new competitors. And some threats include potential loss of reputation or brand effect factors.

\subsection{Constructing a SWOT matrix}

After analyzing the company's strengths, weaknesses, opportunities, and threats, the SWOT matrix is formed according to the priority of the urgency of the situation to develop the strategy of SO, ST, WO, and WT [6]. The SWOT matrix model is shown in Table 2. 


\begin{tabular}{ccc}
\hline Opportunities & $\begin{array}{c}\text { Opportunities Advantage (SO) } \\
\text { Exploiting external opportunities and } \\
\text { exploiting internal strengths }\end{array}$ & $\begin{array}{c}\text { Opportunity Weaknesses (WO) } \\
\text { Exploiting external opportunities to } \\
\text { reduce internal disadvantages }\end{array}$ \\
Threats & $\begin{array}{c}\text { Threat Strengths (ST) } \\
\text { Utilizing inner strengths to overcome } \\
\text { external threats }\end{array}$ & $\begin{array}{c}\text { Threat Disadvantage (WT) } \\
\text { Avoiding external threats and reduce } \\
\text { internal disadvantages }\end{array}$ \\
\hline
\end{tabular}

\section{Results}

\subsection{Advantages of China's e-commerce development}

\subsubsection{E-commerce marketing advantages}

Nowadays, when you turn on an electronic device there may be bombarded with advertising. For example, when you open the software, there may be a pop-up window or you must watch the video before the promotional video, some platforms may cooperate with the network celebrities, let them advertise the products from the platform. Take live stream selling, for example, top Internet celebrities who started to sell products have made millions of yuan in net profit overnight, with an average audience of more than 10,000 people. On August 20, 2021, the data report of "Tik Tok 818 Trendy Goods Festival" was released. According to the report, from August 1 to 18, a total of 23.54 million hours were spent on Tik Tok's live stream, with 30.4 billion views.

\subsubsection{E-commerce scale advantage}

According to Finaria.it, the COVID-19 pandemic has accelerated the shift from physical stores to digital shopping, with millions of consumers worldwide turning to online stores during the COVID19 pandemic, resulting in a 9.5 percent year-on-year jump in the number of e-commerce users to more than 3.4 billion in 2020. The number of e-commerce users is expected to grow by more than $10 \%$ to 3.8 billion in 2021, a still strong growth. As the number of e-commerce users continues to grow, the resulting surge in e-commerce market revenue is obvious, with the global e-commerce market revenue increasing by $25 \%$ year on year to $\$ 2.43$ trillion in 2020. Many online retail platforms saw an unprecedented increase in traffic growth in 2020, even surpassing the holiday peak. The analysis predicts that global e-commerce revenue will exceed $\$ 2.7$ trillion in 2021 and grow to $\$ 3.4$ trillion by 2025 .

\subsection{Disadvantages of China's e-commerce development}

\subsubsection{Security of e-commerce}

Many customers believe that when they are shopping online, the platform or merchants will cheat their personal information. After the buyers have purchased the goods, they will suddenly appear a lot of junk advertising and calls. According to information provided by CCTV, on some well-known e-commerce platforms in China, merchants are selling imported goods, while requiring domestic customers to provide id information. Through further investigation, it is found that after obtaining the customer's ID number, delivery address, and other information, the merchants will collect and upload the information to the cross-border e-commerce platform which means they resist the information by using the customer's ID number so that the imported goods ordered in the customer's name can enjoy the preferential tax rate granted by the country to the cross-border e-commerce platform. This is why 
some buyers fear that online trade will reveal their personal information, so it will also lose customers not only in domestic e-commerce companies but also in cross-border e-commerce platforms.

\subsubsection{The e-commerce management mode is not mature}

The number of buyers is too large, the seller team or the e-commerce platform operation mode is not mature, they are not able to manage the warehouse, resulting in the backlog of goods, so the buyer may find some problems such as quality and quantity after receiving the goods. Especially food, fresh and other goods with a shorter shelf life, or the dress-good because it can be stored for a very long time.

model establishment, but the classical load forecasting method cannot afford such a huge time and computing resource consumption. The problem of overfitting in a large sample set will affect the prediction accuracy. In this paper, a power load forecasting model is built by using the BP neural network model, making full use of the powerful data processing function of Clementine, and preventing the overfitting function. The experimental results show that the BP neural network model has good predictability and robustness and has a certain practical application value.

\subsection{Opportunities for Chinese's e-commerce development under COVID-19}

\subsubsection{The surge in the demand for e-commerce}

The emergence of COVID-19 let people have a longer time at home. The hindrance of offline consumption has led to a large number of people shifting consumer demand to online shopping platforms. The demand and clicks of all major e-commerce platforms have risen sharply. People's consumption habits are gradually being changed [7]. According to Alibaba's third quarter of 2020 financial report, Alibaba's revenue in the third quarter of 2020 was 161.46 billion yuan, an increase of $37.67 \%$ compared with the third quarter of 2019. In addition to traditional domestic commerce platforms such as Taobao, JD.com, the demand for various small and medium-sized e-commerce platforms has also increased. In the 2020 full-year financial report released by Vipshop, the net income of Vipshop was 101.9 billion yuan, a year-on-year increase of $9.5 \%$.

\subsubsection{Advantages under peer competition}

Domestic consumers have greater concerns about cross-border e-commerce products, and their demand has dropped significantly [8]. More and more consumers tend to choose local e-commerce products, which brings opportunities for the development of domestic e-commerce. What's more, cross-border logistics issues have also affected cross-border e-commerce. International logistics and the suspension of commercial flights have significantly increased the cost of time and money. For example, the official UPS Express of the United States stated that from March 26, 2020, all freight UPS service guarantees from any starting point to any destination will be suspended. FedEx also issued a notice regarding the temporary adjustment of surcharges for international shipments.

\subsection{Challenges posed by Covid-19 to China's e-commerce}

\subsubsection{Obstacles to supply and demand}

Affected by the epidemic policy in China, to avoid large-scale crowd gatherings, a great number of workers cannot resume work and production, and production efficiency has been severely influenced. China's Manufacturing Purchasing Managers' Index (PMI) in August released by the China Federation of Logistics and Purchasing and the Service Industry Survey Center of the National Bureau of Statistics was $50.1 \%$, a decrease of 0.3 percentage points from July [9]. The tipping point indicates that the growth rate of the manufacturing industry has slowed down. In the first two to three months of the outbreak, the problem of insufficient supply and inability to produce was even more serious, and the supply of many e-commerce sellers could not be well guaranteed.

\subsubsection{Difficulties in logistics transportation}

E-commerce sellers rely on logistics to transport products to buyers, and logistics issues are critical to e-commerce companies. During COVID-19, although many logistics companies have resumed 
operations, they have been hindered by road closures and the isolation of distribution personnel, which has reduced the efficiency of logistics and transportation. In 2020, the volume of road transport freight decreased by $20.2 \%$ year-on-year in January and $27.2 \%$ year-on-year in February [10]. Moreover, COVID-19 has a strong spread and infectiousness, and the distribution link of logistics mainly relies on manpower, which also increases the pressure of distribution.

\section{Conclusions}

The development of the e-commerce industry is on the rise. During the epidemic, economic development is hampered to some extent. This paper uses the SWOT analysis theory to analyze the strengths, weaknesses, opportunities, and threats of Jing Dong. It analyzes the development of the ecommerce industry by combining the analysis of internal and external environmental factors. During the epidemic, despite the limitations such as logistics and transportation, Jing Dong still plays its advantages of corporate marketing scale and opportunities to optimize the shortcomings of transportation, e-commerce security information. Jing Dong has overcome the market threats facing supply and demand, promoted the innovation and development of the e-commerce model. During the epidemic, it has contributed to the country's economic development, while the development of the ecommerce business model is essential to improve social and economic benefits.

\section{References}

[1] Wang, D, Jia, H, Qi Li, Ren, C. Value creation of Platform Business Model Enterprise-Alibaba-Based case study. [J] Friends of accounting,2021(13): 28-35.

[2] Zeng,Y. Analysis of essence of business model and implementation [J]. Market Modernization,2021(01): 30-32.

[3] Wang, D, Jia, H, Qi Li, Ren, C. Value creation of Platform Business Model Enterprise-Alibaba-Based case study. [J] Friends of accounting, 2021(13): 28-35.

[4] Chen, Y. (2016). SWOT analysis method and its application in strategic management of enterprises. Enterprise Reform and Management (21), 18-19.DOI: 10.13768/j.cnki.cn11-3793/f.2016.4187.

[5] Sarsby, A. (2016). SWOT analysis. Lulu. com

[6] Li JP. (2020). Exploring the application of SWOT analysis in strategic enterprise management. Business News (25), 93-95. DOI: CNKI: SUN: SYJW.0.2020-25-056.

[7] Jun,C. -L. (2020). Opportunities and challenges of e-commerce under the COVID-19. National Circulation Economy (15), 11-13. doi: 10.16834/j.cnki.issn1009-5292.2020.15.003.

[8] Ren, X, Qu, J \& Xia, Z. (2020). Research on e-commerce development countermeasures under the background of COVID-19. Chinese Foreign Investment (20), 19-20. doi: CNKI: SUN: WQZG.0.202020-017.

[9] (2021-09-01). Affected by both the off-season and COVID-19, the growth rate of the manufacturing industry has slowed. Modern Logistics News, 001 .

[10] Liu, L.- H., Chen, X \& Ping, H (2021). The impact of COVID-19 on the logistics industry and countermeasures. Supply Chain Management (01), 97-106. doi: 10.19868/j.cnki.gylgl.2021.01.010. 